\title{
Dimensioning the instrumentation: Exploratory or confirmatory factor analysis?
}

\author{
Re: Quality of nursing care: Instrument development and validation
}

\author{
Shahrzad Ghiyasvandian', Pegah Matourypour' \\ 'Tehran University of Medical science, Nursing \& Midwifery Faculty. Tehran, Iran.
}

Dear Editor,

Martinez et al. in their research entitled as "Quality of nursing care: Instrument development and validation", published in volume 69 and issue 5 in 2016, have done a valuable work in relation to the design and psychometry of instrument as well as the relevant areas (Nurses' perceptions of activities leading to increased quality of care by nurses) $)^{(1)}$.

There are some tips in some parts of the research methodology that need to be considered. Explaining them seems to be capable of improving the work in future research and to be a guidance for other researchers in the field of design and validity of the instrument. Conceptualization and generating items in this study were performed with a deductive approach and by using OE - Ordem dos Enfermeiros (Order of Nurses) standard related to Portugal standards. Sampling in large sample size and focusing on the validity and reliability of the provided tool are as the strengths of the mentioned study.

Papers appraisal is essential for the growth of knowledge and improves the quality of scientific research ${ }^{(2)}$. Scientific review of articles can be useful for readers and researchers regarding the increase of the article quality ${ }^{(3)}$. The mentioned study is criticized from two major aspects:

In evaluating the newly designed instrument validity, only the qualitative content analysis (intelligibility, clarity and communication) has been mentioned. Although this evaluation is proper and accurate, but it is not enough, and CVI or CVR have not been calculated ${ }^{(4-5)}$, while focusing on these indices is crucial in instrumentation and represents the issue that whether the instrument content fully assesses the studied structure or not ${ }^{(5)}$.

The important, and in fact, the main thing to notice is that followed by sampling, the exploratory factor analysis method was used to assess the construct validity, while the dimensions have been specified in the beginning of the study and it is even determined that which items would be placed in which dimensions. In this context, the factor analysis of choice will be of confirmatory type and not the exploratory kind ${ }^{(5-7)}$. Since, the confirmatory type is the test hypothesis, suggesting that whether the statements included within each dimension are really fit and belong to that dimension or not ${ }^{(4)}$. The exploratory type, as the name implies, involves the detection and determining the dimensions. Sometimes, the texts can be used to state the dimensions of a structure. However, to specify which statements need to be placed in the made instrument, the exploratory factor analysis prediction should be employed in such circumstances.

The purpose of the aforementioned is helping the illustration of key points in the design of the instrument and mentioning of some necessary points. Researchers would like to appreciate the Rev Bras Enferm Journal as it accepts the review of articles with contentment, and accordingly, supports the improvement of the articles quality.

CORRESPONDING AUTHOR Pegah Matourypour E-mail: matourypour@yahoo.com

Tehran University of Medical Sciences

1416753955 - Tehran / Iran (the Islamic Republic of) 


\section{REFERENCES}

1. Martins MMFPS, Gonçalves MNC, Ribeiro OMPL, Tronchin DMR. Quality of nursing care: instrument development and validation. Rev Bras Enferm [Internet]. 2016[cited 2016 Dec 10];69 (5):864-70. Available from: http:// www.scielo.br/pdf/reben/v69n5/en_0034-7167-reben-69-05-0920.pdf

2. Salehinia H. Critice an article: How to write a medical article. Iranian J Med Educ. 2014;14(1):87-89.

3. Burns N, Grove S. The practice of Nursing Research. 5th ed: Elsevier / Sunders; 2005.

4. Hajizadeh E, Asghari M. Statistical Methods and Analyses in Health and Biosciences, A Research Methodological Approach, Using SPSS Practical guide. Tehran: Jahade Daneshgahi 2011; p: 395-448.

5. Creswell JW. Research design: Qualitative, quantitative and mixed methods approaches California: Sage publication; 2008.

6. Polit DF, Beck CT. Nursing research: generating and assessing evidence for nursing practice. 9th ed. Philadelphia: Wiliams \& Wilkins; 2013.

7. Hinkin, T. R. A brief tutorial on the development of measures for use in survey questionnaires [Internet]. Cornell University, School of Hotel Administration.1998[cited 2016 Dec 10]. site: htt: //scholarship.sha.cornell.edu/ articles/521

\section{Dear Dr. Shahrzad Ghiyasvandian and Miss Pegah Matourypour}

We value your comments on our paper "Quality of nursing care: Instrument development and validation".

This study was conducted based on the exploratory factor analysis, according to Hair JF Jr, Black WC, Babin BJ, Anderson RE. Multivariate Data Analysis, Pearson, 2013. The purpose of this study was to validate the Scale of Perception of Nursing Activities that Contribute to Nursing Care Quality (EPAECQC) and confirm the existing dimensions, used as a referential model by the Portuguese Order of Nurses, by adding some variables to each one of the dimensions in order to attest the scale's validity. Thus, the exploratory factor analysis was used to assess the content and construct validity and the internal consistency, by means of correlation between the variables. The scale's validity was analysed and then validated after testing the hypothesis of adding or excluding variables. Despite the limitation of this study, which was the fact that the scale was applied to only one Portuguese hospital, we firmly believe that this scale can be applied at Portuguese national level and adapted to international nursing contexts.

Further research is now being conducted using the confirmatory factor analysis, which involves 3451 nurses from different professional status, working in 36 Portuguese hospital facilities.

\section{Authors: Maria Manuela Ferreira Pereira da Silva Martins, Maria Narcisa da Costa Gonçalves, Olga Maria Pimenta Lopes Ribeiro e Daisy Maria Rizatto Tronchin.}

